\title{
PERANCANGAN ALAT SISTEM PENGONTROLAN SUHU DAN KELEMBAPAN RUANG BUDIDAYA ULAT SUTERA BERBASIS WIRELESS
}

\author{
Umar Katu $^{1}$, Rosmilawaty ${ }^{2}$, Anri Iswanto ${ }^{3}$ \\ 1,2,3Program studi Teknik Elektro Fakultas Teknik Universitas Muhammadiyah Makassar \\ e-mail: umark@ymail.com ${ }^{1}$ rosmilawaty5@gmail.com², anri_ucculyahoo.co.id ${ }^{3}$
}

\begin{abstract}
Caterpillar conducting of silk represent one of the effort conducting which often in meeting in some sentra produce silk cloth. Silkworm ( Bombyx Mori L.) representing one of the insect type having high economic value to human being. The insect is silk fibre producer representing textile area silk raw material, surgical operation yarn, and parachute with high kulitas, not yet can be defeated by silk fibre made in. Cycle Live silkworm can grow optimal at ambient temperature 23$28^{\circ} \mathrm{C}$ and dampness $80-90 \%$ RH. If looked after in environment have hotter temperature to hence productivity will be downhill because silkworm is bloodless animal (the mentioned poikilotherm). Pursuant to [the] mentioned, this final duty aim to to [be] is optimal of silkworm productivity designed a system of pengontrolan base on wireless. able to control temperature and dampness of silkworm conducting room as according to requirement that is $23-28^{\circ} \mathrm{C}$ and dampness $80-90 \%$. System control of dampness and temperature with Radio mnggunakan of Frequency module (Module RF) to be presented by at monitor in the form of Personal Computer ( PC). If inappropriate temperature pursuant to read of censor with range that is $23-28^{\circ} \mathrm{C}$, fan will be active and if inappropriate dampness pursuant to read of censor with range that is $80-90 \%$ RH, sprayer will be active.
\end{abstract}

Intisari-Budidaya ulat sutra merupakan salah satu usaha budidaya yang sering di jumpai di beberapa sentra produksi kain sutera. Ulat sutera (Bombyx mori L.) merupakan salah satu jenis serangga yang mempunyai nilai ekonomis tinggi bagi manusia. Serangga tersebut adalah produsen serat sutera yang merupakan bahan baku sutera dibidang pertekstilan, benang bedah, dan parasut dengan kulitas tinggi, belum bisa dikalahkan oleh serat sutera buatan. Siklus Hidup ulat sutera dapat tumbuh optimal pada suhu lingkungan 23-28 ${ }^{\circ} \mathrm{C}$ dan kelembaban $\mathbf{8 0 - 9 0 \%}$ RH. Apabila dipelihara dalam lingkungan bersuhu lebih panas maka produktivitas akan menurun karena ulat sutera adalah hewan berdarah dingin (poikilotherm). Berdasarkan hal tersebut, tugas akhir ini bertujuan untuk mengoptimalkan produktivitas ulat sutera dengan merancang sebuah sistem pengontrolan berbasis wireless yang dapat mengontrol suhu dan kelembaban ruang budidaya ulat sutera sesuai dengan kebutuhan yaitu 23 $28{ }^{\circ} \mathrm{C}$ dan kelembaban $80-90 \%$. System pengontrol suhu dan kelembaban dengan mnggunakan Radio Frequency module (RF module) yang akan ditampilkan pada monitor berupa Personal Computer (PC). Jika suhu tidak sesuai berdasarkan pembacaan sensor dengan range yaitu $23-28^{\circ} \mathrm{C}$, kipas angin akan aktif dan apabila kelembaban tidak sesuai berdasarkan pembacaan sensor dengan range yaitu 80-90 \% RH, sprayer akan aktif.

Kata Kunci :ulat sutra, pengontrol,wirelees.

\section{PENDAHULUAN}

Latar Belakang

Budidaya merupakan kegiatan terencana pemeliharaan sumber daya hayati yang dilakukan pada suatu areal lahan untuk diambil manfaat/hasil panennya di dalam bidang pertanian. Kegiatan budidaya dapat dianggap sebagai inti dari usaha tani.

Budidaya ulat sutra merupakan salah satu usaha budidaya yang sering di jumpai di beberapa sentra produksi kain sutera. Ulat sutera (Bombyx mori L.) merupakan salah satu jenis serangga yang mempunyai nilai ekonomis tinggi bagi manusia. Serangga tersebut adalah produsen serat sutera yang merupakan bahan baku sutera dibidang pertekstilan, benang bedah, dan parasut dengan kulitas tinggi, belum bisa dikalahkan oleh serat sutera buatan.

Walaupun iklim Indonesia cocok untuk budidaya ulat sutera, tetapi kenyataan belum banyak daerah yang mengusahakannya. Di Indonesia, masih tersedia lahan yang cukup luas untuk dipakai usaha budidaya ulat sutera, namun yang menjadi kendala untuk membudiyakan ulat sutera adalah suhu dan 
kelembaban yang kurang ideal.

Dimana ulat sutera dapat tumbuh optimal pada suhu lingkungan $23-28^{\circ} \mathrm{C}$ dan kelembaban $80-90 \%$. Apabila dipelihara dalam lingkungan bersuhu lebih panas maka produktivitas akan menurun karena ulat sutera adalah hewan berdarah dingin (poikilotherm).

Berdasarkan hal tersebut, tugas akhir ini bertujuan untuk mengoptimalkan produktivitas ulat sutera dengan merancang sebuah sistem pengontrolan berbasis wireless yang dapat mengontrol suhu dan kelembaban ruang budidaya ulat sutera sesuai dengan kebutuhan yaitu $23-28{ }^{\circ} \mathrm{C}$ dan kelembaban 80-90 \% Jika suhu tidak sesuai berdasarkan pembacaan sensor dengan range yaitu $23-28^{\circ} \mathrm{C}$, kipas angin akan aktif dan apabila kelembaban tidak sesuai berdasarkan pembacaan sensor dengan range yaitu 80-90 \%, sprayer akan aktif. Suhu dan kelembaban ruang budidaya ulat sutera dimonitor melalui PC.

Rumusan Masalah

Berdasarkan latar belakang masalah di atas, maka dirumuskan masalah yaitu :

1) Bagaimana merancang sistem pengontrolan suhu dan kelembaban ruang budidaya ulat sutera berbasis wireless?

2) Bagaimana pengontrolan suhu dan kelembaban ruang budidaya ulat sutera berbasis wireless?

Tujuan Penelitian

Tujuan dari penelitian ini untuk :

1) Merancang sistem pengontrolan suhu dan kelembaban ruang budidaya ulat sutera berbasis wireless.

2) Membuat pengontrolan suhu dan kelembaban ruang budidaya ulat sutera dengan standar suhu 23-28 ${ }^{\circ} \mathrm{C}$ dan kelembaban $80-90 \%$.

$$
\text { II. TINJAUAN PUSTAKA }
$$

\section{Ulat Sutera (Bombyx mori)}

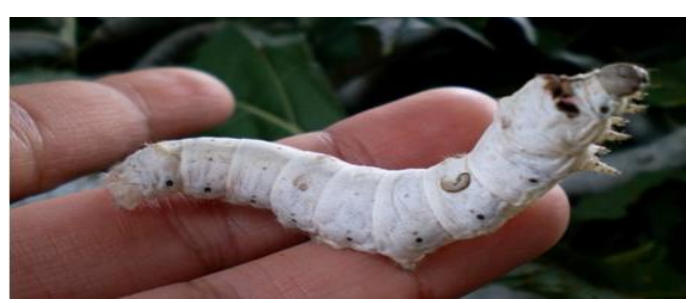

\section{Gambar 1 Ulat sutera instar V}

Bombyx mori adalah sejenis serangga yang mampu menghasilkan benang sutera. Nama Bombyx mori dapat ditelusuri dari perkataan Bombyx sebagai nama jenis serangga penghasil serat yang termasuk dalam famili Bombycidae memiliki nilai ekonomis yang tinggi dan kata mori berasal dari morus (murbei) yang daunnya merupakan bahan makanan ulat sutera.

Berdasarkan habitatnya ulat sutera dibagi dalam dua kelompok. Kelompok pertama adalah ulat sutera liar (wild silkworm) yaitu ulat sutera yang hidup bebas pada beberapa jenis pohon. Kelompok kedua adalah ulat sutera yang biasa dipelihara di dalam ruangan dan merupakan penghasil utama sutera yang meliputi $95 \%$ produksi sutera dunia. Pertumbuhan ulat sutera sangat dipengaruhi oleh kondisi iklim di lokasi pemeliharaan, yaitu suhu, kelembaban, kualitas udara, aliran udara, cahaya, dan sebagainya. Ulat sutera dapat tumbuh optimal pada suhu lingkungan $23-28{ }^{\circ} \mathrm{C}$ dan kelembaban 80-90\%.

\section{Mikrokontroller AVR ATmega8535 Arsitektur AVR ATmega8535}

AVR merupakan seri mikrokontroller CMOS 8-bit buatan Atmel, berbasis arsitektur RISC (Reduced Instruction Set Computer). Hampir semua instruksi 
dieksekusi dalam satu siklus clock. AVR mempunyai 32 register general-purpose, timer/counter fleksibel dengan mode compare, interupt internal dan eksternal, serial UART, programmable Watchdog Timer, dan mode power saving. Beberapa diantaranya mempunyai ADC dan PWM internal. AVR juga mempunyai In-System Programmable Flash on-chip yang mengijinkan memori program untuk diprogram ulang dalam sistem menggunakan hubungan serial SPI. Chip AVR yang digunakan untuk tugas akhir ini adalah ATmega8535.

\section{Pena - pena Atmega8535}

Konfigurasi Pin Mikrokontroller ATmega8535 dengan kemasan 40-pin DIP (dual in - line package) Untuk memaksimalkan performa dan paralelisme, AVR menggunakan arsitektur Harvard (dengan memori dan bus terpisah untuk program dan data). Instruksi pada memori program dieksekusi dengan pipelining single level. Selagi sebuah instruksi sedang dikerjakan, instruksi berikutnya diambil dari memori program.

\section{Port Sebagai Input /Output Digital}

ATmega8535 mempunyai empat buah port yang bernama PortA, PortB, PortC, dan PortD. Keempat port tersebut merupakan jalur bi-directional dengan pilihan internal pull-up.
Tiap port mempunyai tiga buah register bit, yaitu DDxn, PORTxn, dan PINxn. Huruf ' $x$ ' mewakili nama huruf dari port sedangkan huruf ' $n$ ' mewakili nomor bit. Bit DDxn terdapat pada I/O address DDRx, bit PORTxn terdapat pada I/O address PORTx, dan bit PINxn terdapat pada I/O address PINx. Bit DDxn dalam regiter DDRx (Data Direction Register) menentukan arah pin. Bila DDxn diset 1 maka Px berfungsi sebagai pin output. Bila DDxn diset 0 maka Px berfungsi sebagai pin input. Bila PORTxn diset 1 pada saat pin terkonfigurasi sebagai pin input, maka resistor pull-up akan diaktifkan. Untuk mematikan resistor pull-up, PORTxn harus diset 0 atau pin dikonfigurasi sebagai pin output. Bit 2 - PUD : Pull-up Disable

Bila bit diset bernilai 1 maka pull-up pada port I/O akan dimatikan walaupun register DDxn dan PORTxn dikonfigurasikan untuk menyalakan pull-up $(\mathrm{DDxn}=0$, PORTxn=1).

\section{Humidity Sensor SHT11}

SHT11 Module merupakan modul sensor suhu dan kelembaban relatif dari Sensirion. Modul ini dapat digunakan sebagai alat pengindra suhu dan kelembaban dalam aplikasi pengendali suhu dan kelembaban ruangan maupun aplikasi pemantau suhu dan kelembaban relatif ruangan. 


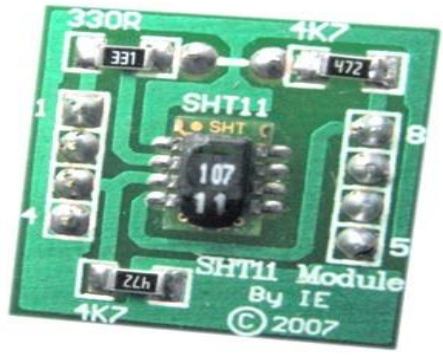

Gambar 2 Module SHT11

\section{Prinsip Kerja Sensor}

SHT11 adalah sebuah single chip sensor suhu dan kelembaban relatif dengan multi modul sensor yang outputnya telah dikalibrasi secara digital. Dibagian dalamnya terdapat kapasitas polimer sebagai eleman untuk sensor kelembaban relatif dan sebuah pita regangan yang digunakan sebagai sensor temperatur.

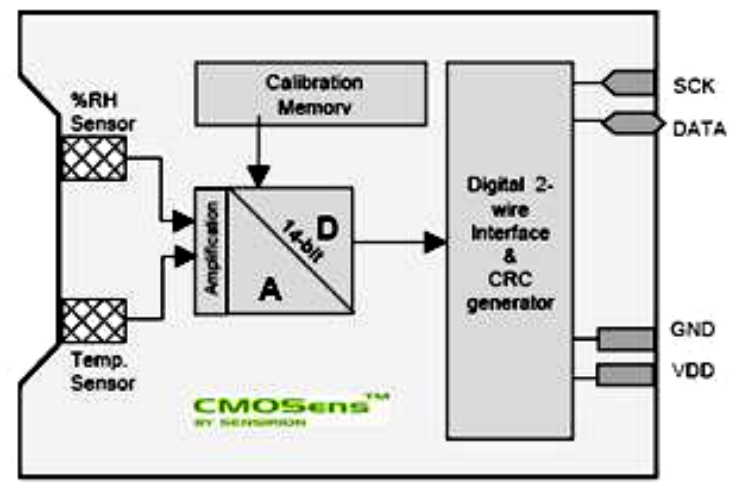

Gambar 3 Diagram blok SHT11

Skema pengambilan data SHT11 dapat dilihat pada gambar berikut ini.

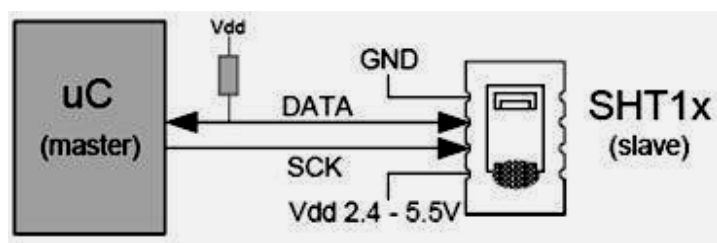

Gambar 4 Skema data SHT11
Relay

Relay adalah saklar magnet. Keunggulannya terhadap saklar mekanik biasa adalah dapat dipakai dengan aman untuk mengemudikan (on/off) suatu sistem dari jarak jauh karena bekerja dengan arus dan tegangan yang kecil sebagai pemicu untuk menyambungkan atau memutuskan suatu peralatan dengan sumber arus listrik yang besar.

\section{YS1020 RF Modul}

YS-1020 series Low Power RF

Module didesain untuk sistem transmisi data UARTjarak dekat. YS-1020 merupakan adaptasi Texas Instruments (Chipcon) CC1020 RF IC,bekerja pada ISM frequency band, transmisi half duplex. Modul dapat langsung dengan monolitik prosesor, PC, perangkat RS485, dan komponen UART lain dengan RS232, RS485, dan TTL interface port.

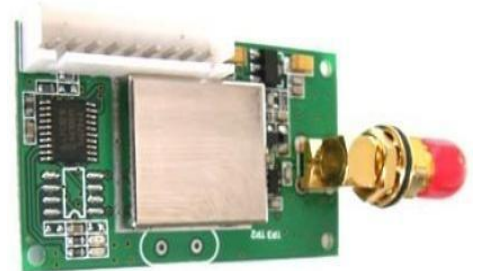

Gambar 5 RF Data Transceiver YS-1020ua

RF Data Transceiver ini biasa digunakan untuk berbagai aplikasi industri maupun rumah tangga. Sebagai contoh adalah sebagai wireless remote control, sistem telemetri, monitoring, dan lain-lain.

\section{Catu Daya}


Catu daya merupakan suatu basic compiler berbasis windows untuk rangkaian yang paling penting bagi sistem mikrokontroler keluarga AVR, merupakan elektronika. Rangkaian catu daya DC dapat pemrograman dengan bahasa tingkat tinggi diperoleh dari penyearahan tegangan AC "BASIC" yang dikembangkan dan yang disusun dari transformator, penyearah, dikeluarkan oleh MCS elektronika sehingga dan regulator tegangan.

Tegangan AC dari jala-jala PLN dapat dengan mudah dimengerti atau diterjemahkan.

diturunkan nilainya oleh transformator step

BASCOM-AVR

pilihan yang dapat program. Program simulasi ini bertujuan untuk menguji suatu aplikasi yang dibuat dengan pergerakan LED yang ada pada layar simulasi dan dapat juga langsung dilihat pada LCD, jika kita membuat aplikasi yang berhubungan dengan LCD.

\section{Wireless}

Wireless Adalah Suatu teknik komunikasi atau pertukaran data jarak dekat/jauh tanpa menggunakan kabel. Mekanisme telekomunikasi nirkabel memungkinkan komunikasi jarak jauh dengan lokasi yang tidak mungkin atau relatif sulit untuk dihubungkan dengan kabel, misalnya dalam bentuk pemancar/penerima radio, pengendali jarak jauh, jaringan komputer nirkabel. Umumnya telekomunikasi nirkabel menggunakan sarana gelombang elektromagnetik (misalnya laser, cahaya, frekuensi radio (RF) atau gelombang suara untuk mentransfer informasi tanpa menggunakan kabel.

\section{Bahasa Pemrograman}

BASCOM-AVR

BASCOM-AVR adalah program

\section{Borland Delphi 7}

Borland Delphi merupakan suatu bahasa pemrograman yang memberikan berbagai fasilitas pembuatan aplikasi untuk mengolah teks, grafik, angka, database dan aplikasi web. Program ini mempunyai kemampuan luas yang terletak pada produktifitas, kualitas, pengembangan perangkat lunak, kecepatan kompilasi, pola desain yang menarik serta bahasa pemrogramannya terstruktur dan lengkap. Fasilitas pemrograman dibagi dalam dua kelompok yaitu object dan bahasa pemrograman.

\section{METODE PENELITIAN}

\section{Waktu}

Pembuatan aplikasi ini akan dilaksanakan selama 6 bulan, mulai dari 
bulan Juli 2015 sampai dengan Desember 2015.

\section{Tempat}

Penelitian ini dilakukan di Program

Studi Teknik Elektro Fakultas teknik

Universitas Muhammadiyah Makassar. memonitorinng suhu dan kelembaban. Jika suhu dan kelemmbabn sudah kembali normal maka akan dikirimkan sinyal untuk menonaktifkan kipas dan spreyer.

\section{Blok Diagram Sistem}

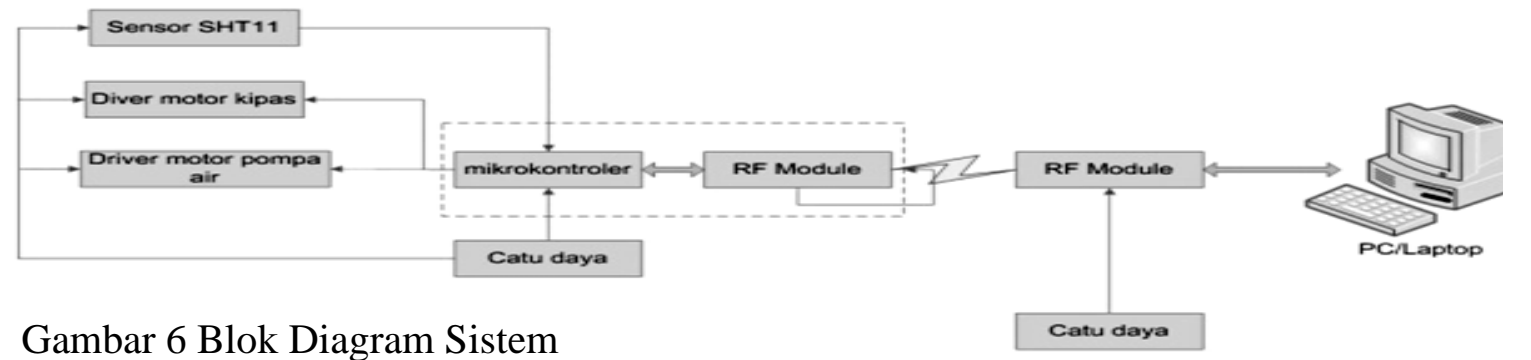

Sistem yang dirancang bertujuan untuk mengontrol dan memonitoring suhu dan kelembaban pada ruang budidaya ulat sutera berbasis wireless. Pada alat ini dibangun dari sistem pengukuran yang terdiri atas mikrokontroler ATMega 8535, sensor suhu SHT11 (suhu dan kelembaban), modul YS1020, dan alat tambahan seperti kipas dan sprayer yang semuanya menjadi satu sistem.

Sensor yang digunakan adalah sensor SHT11, yang dimana sensor ini dirancang untuk dapat mengukur suhu dan kelembaban udara.Sensor ini sudah mampu membaca suhu dan kelembaban dengan keakuratan yang cukup baik. Selanjutnya data yang telah terbaca pada sensor akan dikirimkan ke mikrokontroler kemudian dikirim ke PC, PC akan membandingkan suhu dan kelembaban yang diterima. Jika suhu dan kelembaban di luar dari range habitat hidup ulat sutera , maka akan dikirmkan sinyal untuk mengaktifkan kipas dan sprayer sambil tetap

Perancangan system merupakan tahapan penting yang perlu diperhatikan sebelum memasuki tahapan membuat dan merakit suatu peralatan, baik perangkat keras maupun perangkat lunak.

Tujuan dari perancangan proyek akhir ini adalah untuk merancang system pengontrolan suhu dan kelembaban ruang budidaya ulat sutera dengan menggunakan RF module yang akan ditampilkan pada monitor berupa personal computer (PC) dan mendapatkan sebuah tampilan data pengukuran suhu dan kelembaban yang tepat.

\section{Prosedur Perancangan}

Agar dicapai suatu hasil yang optimal sesuai dengan perancangan, maka dilakukan langkah-langkah perancangan sebagai berikut:

1) Mengidentifikasi masalah. 
2) Menguji rangkaian pengirim serta penerima sebagai sensor temperature dan kelembaban.

3) Menguji sistem minimal mikrokontroler Atmega8535 sebagai pengendali sistem secara keseluruhan.

4) Merancang parangkat lunak sistem.

5) Menguji interface mikrokontroler dengan modul RF YS1020.

6) Menguji kinerja sistem secara keseluruhan serta mengambil data dari hasil perancangan.

7) Menganalisa hasil dan membuat kesimpulan.

\section{Alat dan Bahan yang Digunakan}

Dalam metode perancangan dan pembuatan ini diperlukan sejumlah alat dan bahan sebagai berikut:
Alat
1) Solder listrik
2) Obeng (+) (-)
3) Tang pemotong
4) Tang penjepit

\section{Bahan}

1) Sensor Humidity SHT11

2) MikrokontrolerAVR Atmega8535

3) YS 1020 RF Modul

4) Catu daya

5) Relay

6) RS 232

$\begin{aligned} & \text { Perancangan } \\ & \text { (Hardware) }\end{aligned}$
Perangkat

\section{Sensor SHT11}

SHT (single chip) adalah sensor suhu dan kelembaban relatif yang mempunyai banyak sensor module yang terdiri dari sebuah pengkaliabrasi output digital. Pada pengukuran suhu data yang dihasilkan 14 bit sedangkan untuk

kelembaban data yang dihasilkan 12 bit. Keluaran dari SHT11 adalah di sehingga untuk mengaksesnya diperlukan pemrograman dan tidak diperlukan pengkondisi sinyal atau ADC.

\section{Rangkaian Mikrokontroler}

Rangkaian mikrokontroler Atmega 8535 berfungsi sebagai alat untuk memproses masukan dari sensor SHT11. Selain sebagai alat proses, mikrokontroler tersebut juga mengkontrol blok display yang digunakan sebagai keluaran informasi dari perubahan suhu dan kelembaban yang ada pada suatu ruangan atau tempat.

\section{Rangkaian RF Module YS1020}

Dalam perancangan hardware ini, komunikasi antara mikrokontroler dankomputer bersifat wireless sehingga diperlukan RF module yang berfungsi sebagai sistem transmisinya. Dalam perancangan komunikasi $\mathrm{RF}$ digunakan suatu modul RF transceiver YS1020. RF module ini telah diatur pada frekuensi 433.025 MHz dengan baudrate 19200 bps. Sehingga perancangan untuk komunikasi RF module, mikrokontroler, dan komputer 
adalah sebagai berikut.
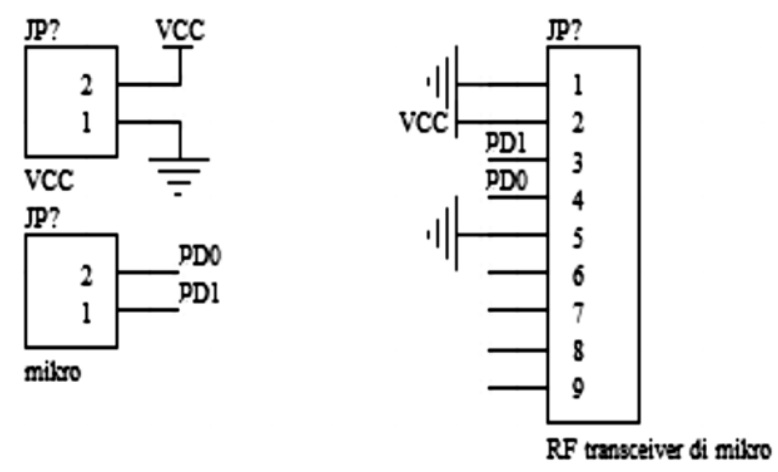

Gambar 7 Rangkaian RF module

\section{Rangkaian Catu Daya}

Dalam perancangan hardware ini diperlukan rangkaian catu daya sebanyak 2 buah. Rangkaian catudaya 5 volt dan 12 volt digunakan untuk mencatu mikrokontroler, RF module, SHT11.

\section{Perancangan Perangkat Lunak (Software)}

Perancangan software ini diperlukan agar sistem dapat bekerja dengan baik. Perancangan software ini meliputi program kontrol dan program tampilan. Perancangan program kontrol dengan complier BASCOM AVR dengan bahasa basic. Sedangkan perancangan program tampilan menggunakan bahasa pemrograman Borland Delphi.

\section{Perancangan Program $\quad$ pada Mikrokontroler}

Bahasa yang digunakan adalah bahasa basic dengan menggunakan aplikasi BASCOM AVR yang akan dimasukkan ke dalam mikrokontroler. Aloritma pada program mikrokontroler adalah sebagai berikut:
1) Inisialisasi port-port dan nilai variable yang akan digunakan. Untuk awal program, inisialisasi nilai thershold suhu adalah 28 dan kelembaban adalah 90 . Maksud nilai 28 tersebut adalah batas suhu dimana kipas akan mulai diaktifkan. Ketika suhu lebih dari $28^{\circ} \mathrm{C}$, maka kipas akan hidup. Sedangkan nilai 80 adalah batas kelembaban dimana sprayer akan mulai diaktifkan. Ketika kelembaban kecil dari 0\%, maka sprayer akan hidup.

2) Setelah inisialisasi, mikro akan menunggu sinyal dari detektor suhu dan kelembaban. Kemudian suhu dan kelembaban itu diterjemahkan menjadi teks yang menjadikan suhu dan kelembaban atau di luar range habitat hidup ulat sutera secara real time dan mengirimkan teks ini ke sistem mmonitoring suhu dan kelembaban.

3) Data suhu dan kelembaban yang terindikasi akan tampil di layar PC.

4) Untuk mengaktifkan kipas dan sprayer maka nilai threshold yang telah ditentukan sebelumnya dibandingkan dengan data suhu dan data kelemaban terbaru

5) Setelah data suhu dan kelembaban dibandingkan dengan nilai threshold sistem monitoring akan mengirimkan sinyal pada mikrokontroler untuk mengaktifkan driver motor kipas dan sprayer. 
Perancangan Program Aplikasi di Monitor

Data yang dikirim oleh mikrokontroler melalui RF modul pada bagian pengirim akan diterima oleh $\mathrm{RF}$ dibagian penerima yang kemudian akan ditampilkan pada komputer melalui suatu program yaitu Borland Delphi yang telah dibuat sebelumnya. Software pada bagian ini sebagai sistem antarmuka (interface) untuk menampilkan data suhu dan kelembaba dalam bentuk grafik secara real time.

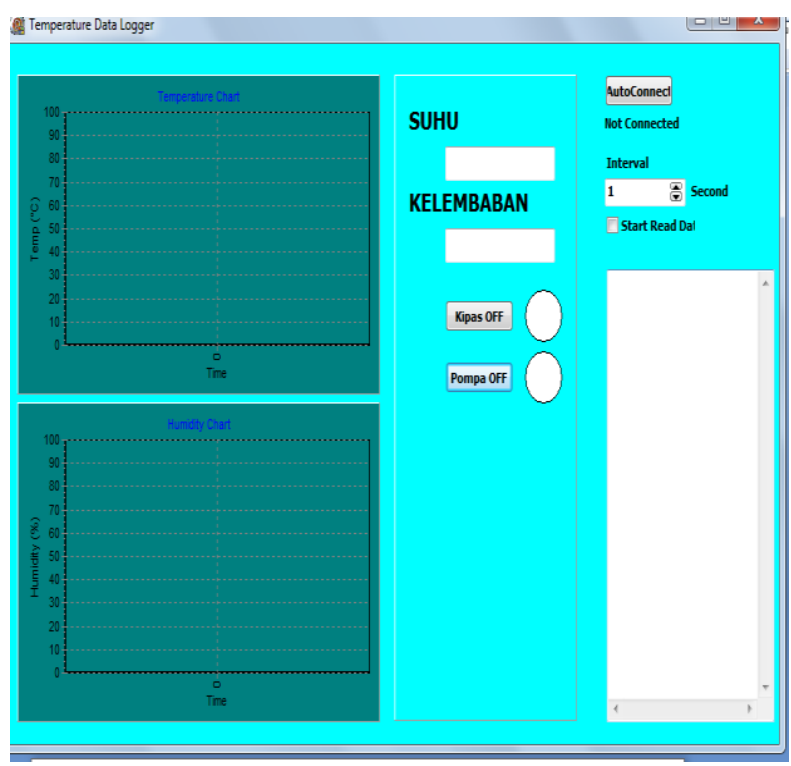

Gambar 8 Tampilan form Borland Delphi

\section{Flowchart}

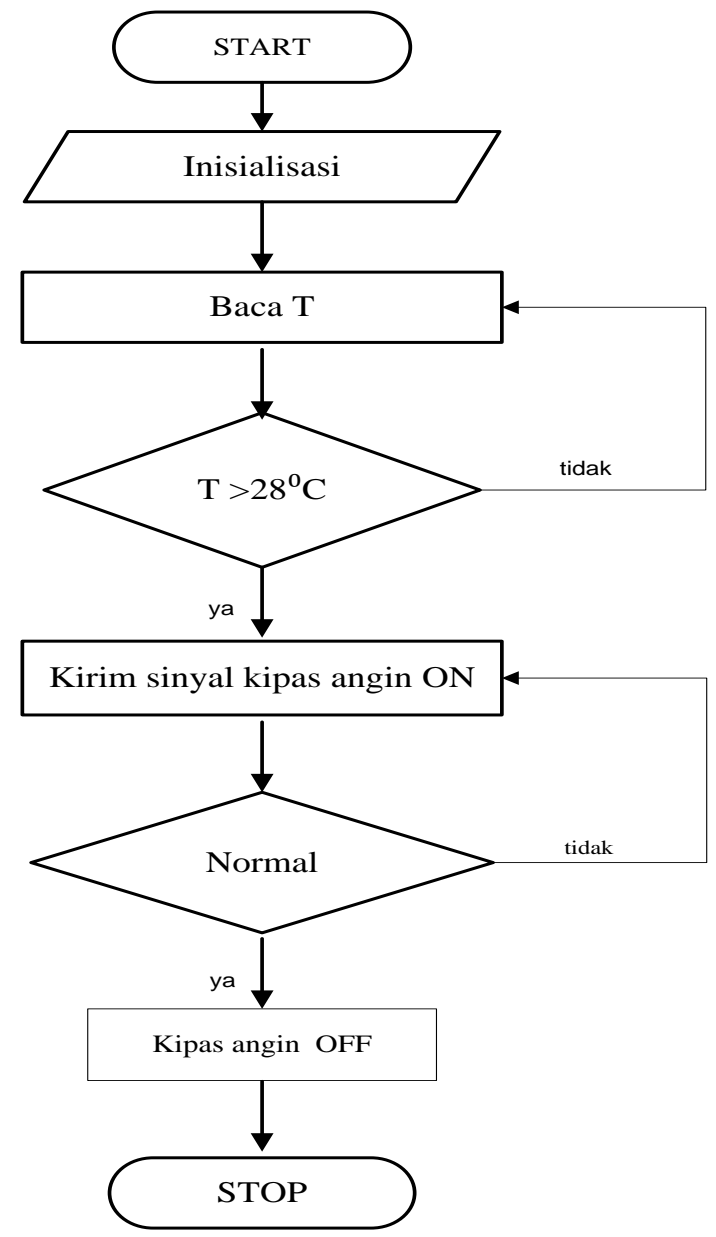

Gambar 9 Flowchart alir pembacaan suhu

\section{HASIL DAN PEMBAHASAN}

\section{Tujuan Pengukuran}

Pengukuran dilakukan dengan tujuan untuk mendapatkan hasil yang sesuai dengan teori, untuk menganalisa program sesuai dengan hasil perancangan dan untuk menganalisa berfungsi atau tidaknya system rangkaian.

\section{Pengujian Sistem Monitoring}

\section{Pengujian monitoring pada PC/Laptop}

Program yang dibuat dilakukan pengujian untuk mengetahui sejauh mana program ini dapat bekerja dengan baik. 
Pengujian yang dilakukan untuk melihat data suhu dan kelembaban yang dapat diterima oleh komputer.

Tabel 1 Hasil pengukuran suhu dan kelembaban yang diterima computer

\begin{tabular}{|l|l|}
\hline \multicolumn{2}{|l|}{ Data diterima computer } \\
\hline Suhu $\left({ }^{\circ} \mathrm{C}\right)$ & $\begin{array}{l}\text { Kelembaban } \\
(\%)\end{array}$ \\
\hline 33,9 & 49,6 \\
\hline 33,9 & 50,7 \\
\hline 32,6 & 51,2 \\
\hline 32,4 & 51,4 \\
\hline 32,5 & 51,3 \\
\hline 32,4 & 51,2 \\
\hline---- & ---- \\
\hline
\end{tabular}

\section{Pengujian Sistem Kontrol}

Pengujian ini dimaksudkan untukmengetahui system control pada ruang budidaya ulat sutera berbasis wireless dapat mengendalikan suhu $23^{\circ} \mathrm{C}-28^{\circ} \mathrm{C}$ dan kelembaban $80 \%$ RH - 90\%RH.

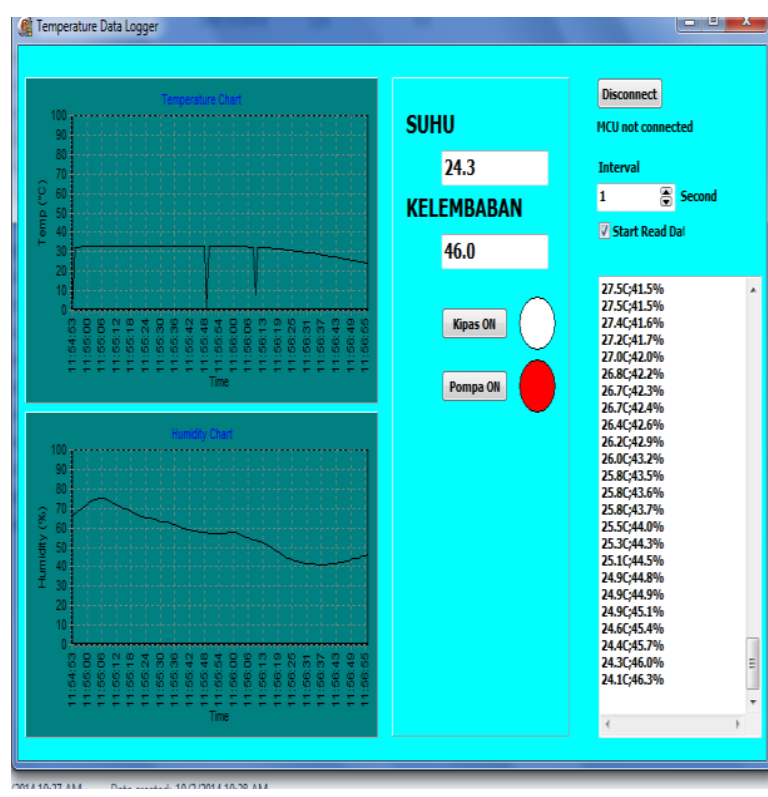

Gambar 12 Kipas off pompa on (merah)

Dari data hasil pengukuran dimana kondisi normal di katakan tercapai jika suhu dan kelembaban sesuai dengan nilai yang diinginkan yaitu suhu $23^{\circ} \mathrm{C}-28^{\circ} \mathrm{C}$ dan kelembaban $80 \%$ RH - 90\%RH. Jika suhu dan kelembaban berada di luar range maka sistem monitoring pada PC akan mengirimkan sinyal pada mikro kontroler untuk mengaktifkan kipas dan sprayer.

Dari hasil pengukuran ini dapat disimpulkan bahwa sistem kontrol yang dibuat berfungsi dengan baik serta mampu mengendalikan suhu dan kelembaban dengan tepat.

\section{Pengujian Jarak Jangkau Wireless}

Pengujian terhadap modul YS1020 dilakukan dengan melakukan pengiriman data dari transmitter ke receiver, kemudian data yang dikirim di bandingkan dengan data yang diterima. Model Pengujian yang lain adalah dengan menguji kemampuan daya pancar modul wifi, dengan memberikan variasi jarak antara transmitter dan receiver..

Dari hasil pengamatan antara data yang tampil di komputer diperoleh data sebagai berikut :

Tabel 2 Pengujian Jarak Jangkau Wireless (indoor)

\begin{tabular}{|l|c|c|l|}
\hline \multirow{2}{*}{$\begin{array}{c}\text { Jarak } \\
\text { jangkauan } \\
\text { wireless }\end{array}$} & \multicolumn{2}{|c|}{$\begin{array}{c}\text { Data diterima } \\
\text { komputer }\end{array}$} & \multirow{2}{*}{$\begin{array}{c}\text { Keterangan } \\
\left({ }^{\circ} \mathrm{C}\right)\end{array}$} \\
\cline { 2 - 3 } & $\begin{array}{c}\text { Suhu } \\
(\%)\end{array}$ & \\
\hline $1 \mathrm{~m}$ & 33,9 & 49,6 & Telembaban di PC) \\
\hline $5 \mathrm{~m}$ & 33,9 & 50,7 & Terkirim \\
\hline $10 \mathrm{~m}$ & 32,6 & 51,2 & Terkirim \\
\hline
\end{tabular}




\begin{tabular}{|l|c|c|l|}
\hline $15 \mathrm{~m}$ & 32,4 & 51,4 & Terkirim \\
\hline $20 \mathrm{~m}$ & 32,5 & 51,3 & Terkirim \\
\hline $25 \mathrm{~m}$ & 32,4 & 51,2 & Terkirim \\
\hline $30 \mathrm{~m}$ & ---- & ---- & TidakTerkirim \\
\hline
\end{tabular}

Dari data yang diperoleh diatas dapat dilihat bahwa data dapat terkirim dengan sempurna. Untuk jarak jangkau wireless dengan percobaan dalam ruangan (indoor) dari 1-25 $\mathrm{m}$ data dapat terkirim dan terbaca di PC. Dan pada jarak $30 \mathrm{~m}$ suhu dan kelembaban yang di tampilkan di PC tidak terkirim.

\section{PENUTUP}

\section{Kesimpulan}

Setelah

dilakukan

proses

perencanaan, pembuatan dan pengujian alat, dapat disimpulkan hal-hal sebagai berikut:

1) Perancangan sistem pengontrolan suhu dan kelembaban ruang budidaya ulat sutera ini dapat bekerja pada suhu $23^{\circ} \mathrm{C}-$ $28^{\circ} \mathrm{C}$ dan kelembaban $80 \%-90 \%$ sesuai dengan habitat asli dari ulat sutera.

2) Perangkat sistem pengontrolan berbasis wireless berjalan dengan baik dimana sistem monitoring suhu dan kelemababan secara otomatis mengirimkan sinyal ke mikrokontroler untuk mengaktifkan kipas dan sprayer ketika suhu dan kelembaban tidak sesuai dengan trheshold yang ditetapkan yaitu suhu $23^{\circ} \mathrm{C}-28^{\circ} \mathrm{C}$ dan kelembaban $80 \%$ - 90\% RH.

\section{Saran}

1) Penambahan setting point pada sistem pengontrolan budidaya ulat sutera diperlukan untuk menyesuaikan suhu dan kelembaban pada setiap siklus hidup ulat sutera.

2) Fungsi dari alat, diharapkan bisa dikembangkan lagi agar tidak hanya bisa mengukur dan mengendalikan suhu dan kelembaban saja, tetapi bisa untuk variable lainnya.

3) Agar modul YS1020 dapat mengirimkan data lebih jauh sebaiknya ditempatkan pada tempat yang tidak mempunyai halangan.

\section{DAFTAR PUSTAKA}

Agfianto, Eko Putra, "Belajar Mikrokontroler ATmega16 Teori dan Aplikasi", edisi kedua ,Yogyakarta: Gava Media,2014,ch:5,pp:163-188.

Agus Nunuh SN, Oke Andikarya, "Budidaya Sutra Alam (Bombyx mori Lin), Cianjur 2006.

Budiharto, Widodo. 2014. Perancangan Sistem dan Aplikasi Mikrokontroler. Jakarta: P.T. ELEX Media Komputindo.

Barmawi, Malvino. 1991.” Prinsip-prinsip Elektronika,". Jilid 1. Erlangga: Jakarta.

Barmawi, Malvino. 1991." Prinsip-prinsip Elektronika,". Jilid 2. Erlangga: Jakarta.

Bishop, Owen 2004, Dasar-Dasar Elektonika, Erlangga, Jakarta.

http://elektronika-dasar.com/teorielektronika/definisi-kapasitor/ diakses pada tanggal 3 September 2015.

http://id.shvoong.com/socialsciences/communication-media- 
studies/2236444-pengertian-borlanddelphi/\#ixzz2M6kpyqTn.

Madcoms. (2003). Pemprograman Borland Delphi 7. Yogyakarta: Andi.

Putra, Agfianto Eko. 2010. Mudah Menguasai Mikrokontoler Atmel AVR menggunakan BASCOM-AVR Yogyakarta, Kelompok Riset DSP dan Embedded Intelgent System-ELNIS.

Rashid M. H., 1993, Elektronika Daya ( Rangkaian, Devais dan Aplikasinya), Edisi Kedua, PT Prenhalindo, Jakarta.

www.atmel.com diakses pada tanggal 3 September 2015.

www.ilmukomputer.com diakses pada tanggal 3 September 2015. 